doi: $10.15407 /$ ujpe61.09.0774

A.S. SIZHUK

Faculty of Radiophysics, Electronics, and Computer Systems, Taras Shevchenko National University of Kyiv

(64/13, Volodymyrs'ka Str., Kyiv 01601, Ukraine; e-mail: cannabiss@mail.univ.kiev.ua)

\title{
THE TRANSMISSION SPECTRUM OF THE MIXTURE OF CO AND HF FOR THE TIME-DEPENDENT DENSITY OF CO
}

\begin{abstract}
The gas phase spectra of a mixture of hydrogen fluoride (HF) and carbon oxide (CO) are obtained for the interval from 3838 to $3854 \mathrm{~cm}^{-1}$. Using the Fourier transform infrared (FTIR) broadband spectroscopy technique, the arising $P$-heads of the fundamental and hot bands of $O C-H F$ complex are observed with increasing the pressure of the CO component, while the HF compound has a fixed amount of molecules. The dependence of the integral change in the transmitted intensity on the pressure of carbon monoxide is analyzed in vicinities of the Pheads of the fundamental band at $3939.12 \mathrm{~cm}^{-1}$ and the hot band at $3944.5 \mathrm{~cm}^{-1}$.

Keywords: Fourier spectroscopy, hydrogen fluoride, carbon monoxide, time-dependent density.
\end{abstract}

\section{Introduction}

There are a lot of investigations devoted to the OCHF complex in the available literature (see, e.g., $[1,5,6,14])$. The experimental and theoretical data on the spectrum of the OC-HF (CO-HF) complexes mostly reflect the properties of a single molecule under isolated conditions (theoretically or experimentally for the gas mixtures rarefied to a few Torr at temperatures below -30 Celsius or supersonic jet expansions).

Inasmuch as under the given conditions, the amount of weakly bound compounds in a mixture depends on the concentrations of each component, the following question can be of interest. Can the sequence of spectroscopic scans under certain fixed conditions and with one varying parameter be used to describe the preconditions of a weak reaction (or, in other words, the creation of a bound state of two molecules, here $\mathrm{CO}$ and $\mathrm{HF}$ )? The certain type of problems can be solved in the term of chemi-

(c) A.S. SIZHUK, 2016

774 cal kinetics (see, e.g., [15]) or by using a new technique [16]. In comparison with the mentioned methods, we will demonstrate the result of Fourier infrared broad band scanning for the mixture with the time-dependent density of carbon monoxide. The retrospective graphics is used to formulate a hypothesis about the mechanism of creation of the complexes during collisions.

The gas phase spectra of the mixture of hydrogen fluoride (HF) and carbon oxide (CO) were obtained for the interval from 3838 to $3854 \mathrm{~cm}^{-1}$. Using the Fourier transform infrared (FTIR) broadband spectroscopy technique, the arising $P$-heads of the fundamental and hot bands of the OC-HF complex are observed with increasing the pressure of the CO component, while the HF compound has a fixed amount of molecules.

The scanning sequence demonstrated in Fig. 1 is performed without interruption in time. If the disalignment of mirrors in the multipath chamber is neglected, the main contribution to the experimental error is the instrumental one. Mainly, the used ther-

ISSN 2071-0194. Ukr. J. Phys. 2016. Vol. 61, No. 9 


\section{Transmission (absorption) spectrum CO + HF, CO time dep. density}

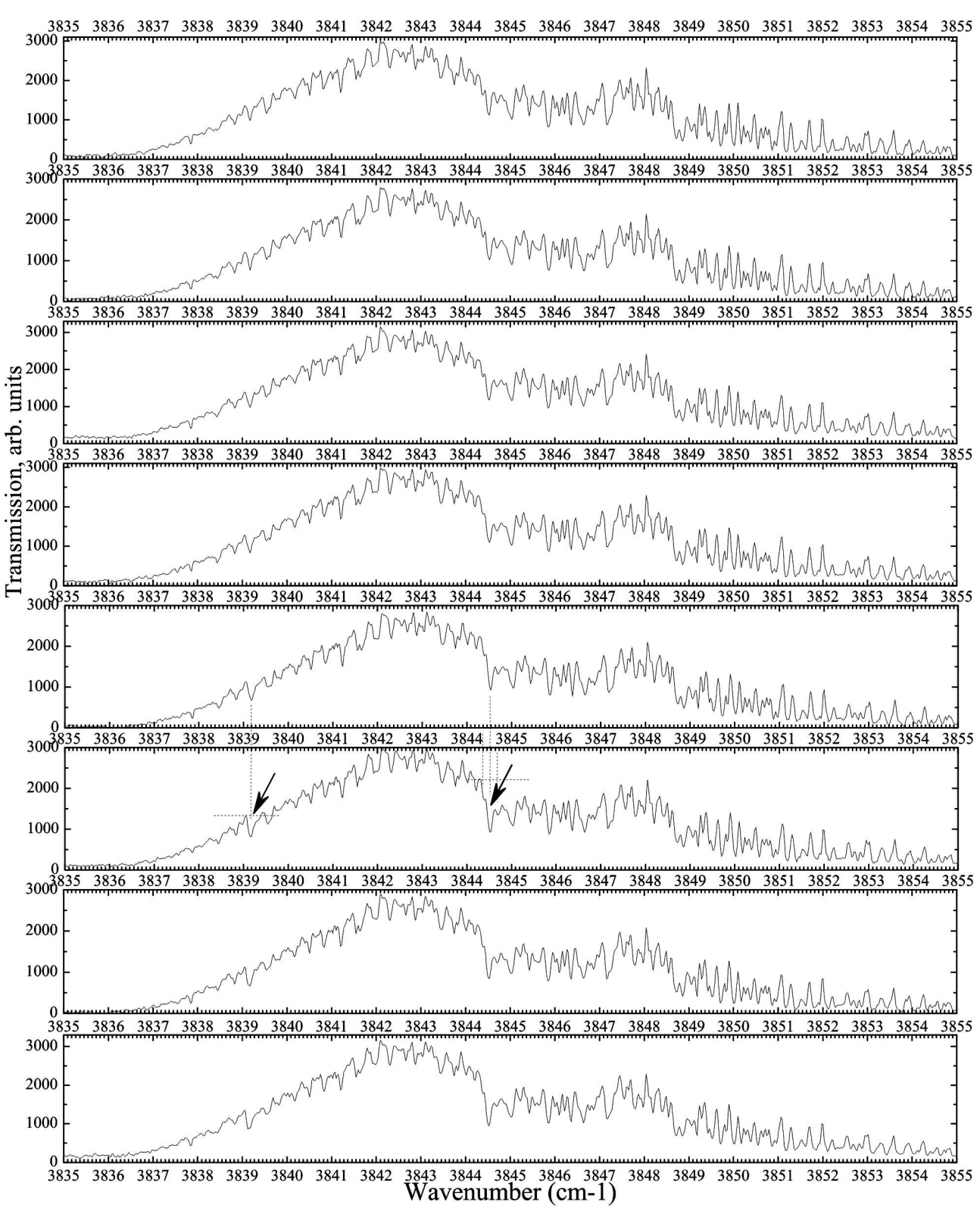

Fig. 1. Absorption spectrum of $\mathrm{OC}-\mathrm{HF}$ at pressures of 2, 4, 6, 8, 10, 12, 14, and 16 Torr (from the upper spectrum downward, respectively) of $\mathrm{CO}$ and a fixed pressure of 16 Torr of HF for an average temperature of $-15 \mathrm{~K}$

mometer and manometer are supposed to give measurements with maximum $\pm 0.5 \mathrm{~K}$ and \pm 0.5 Torr inaccuracies, respectively. Our experimental data were obtained under certain conditions of the gas phase of the mixture (temperatures, pressures, resolutions, etc.), by using a BOMEM DA8 Fourier transform spectrometer system with a multiple-path White cell (stainless steel chamber about $2 \mathrm{~m}$ in length and $0.18 \mathrm{~m}$ in diameter) and a cryogenic cooling system with a detector InSb (1800-14000 $\left.\mathrm{cm}^{-1}\right)$, win- 


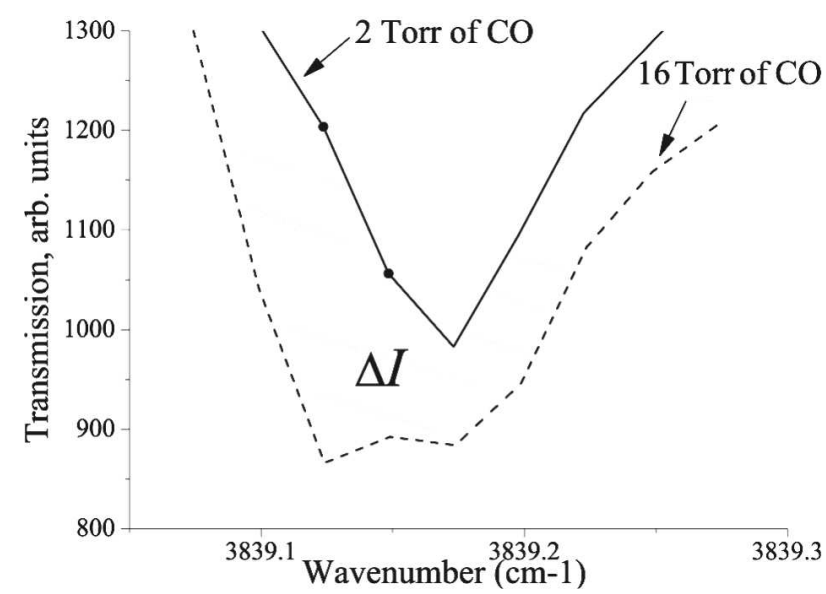

Fig. 2. Vicinity of the $P$-head of the fundamental $\nu_{1}$ band on a larger scale with a step of $0.02472 \mathrm{~cm}^{-1}$. The absorption spectrum of $\mathrm{OC}-\mathrm{HF}$ at pressures of 2 (solid line) and 16 (dashed line) Torr of $\mathrm{CO}$ and 16 Torr of $\mathrm{HF}$ at a fixed average temperature of $-15 \mathrm{~K}$

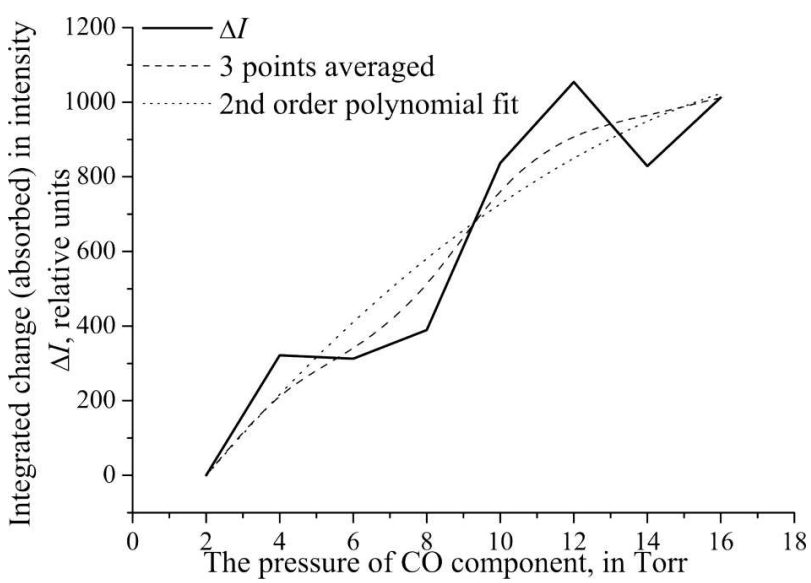

Fig. 3. Integral change in the transmitted intensity $\Delta I$ as a function of the density of carbon monoxide. A vicinity of the $P$-head of the fundamental $\nu_{1}$ band is depicted. Here, the bold polyline connects the values of $\Delta I$ for different pressures of $\mathrm{CO}$ with a step of 2 Torr. The dotted curve represents the secondorder polynomial fit: $\Delta I \sim B_{1} n(\mathrm{CO})+B_{2} n^{2}(\mathrm{CO})$, where $B_{1}=$ $=126.6689$ and $B_{2} \approx-2.9718$. The dashed curve is a threepoint averaged polyline

dows $\mathrm{CaF}_{2}$ (with path band 1200-8500 $\mathrm{cm}^{-1}$ ), and "Quartz" light source $\left(2000-25000 \mathrm{~cm}^{-1}\right)$. In these experiments, a InSb detector cooled with liquid nitrogen is used with an instrumental resolution of $0.05 \mathrm{~cm}^{-1}$. The number of scans is set to 20 . The aperture was set to $1.0 \mathrm{~mm}$, and Base Gain to 1. The temperature gradient along a White cell is mea- sured to be about $5 \mathrm{~K}$ between two extremes of the multipass cell. Respectively, the average temperature is provided. The optical path length is adjusted to about $52 \mathrm{~m}$.

In Fig. 1, we can see the rotationally unresolved $v_{1} \mathrm{H}-\mathrm{F}$ stretching fundamental band of the $\mathrm{OC}-\mathrm{HF}$ complex near the $P$-head at $3839.12 \mathrm{~cm}^{-1}$. On all of them, the possible " $P$ "-head of the $v_{1}+v_{3}-v_{3}$ band is visible at $3847.85 \mathrm{~cm}^{-1}$.

In the sense of the possible assignment, we can see the formation of $P$-heads in Fig. 1 (shown by arrows) at approximately $3839.12 \mathrm{~cm}^{-1}$ for the $v_{1} \mathrm{H}-\mathrm{F}$ stretching fundamental band in the $\mathrm{OC}-\mathrm{HF}$ and at $3844.5 \mathrm{~cm}^{-1}$ for the hot band $v_{1}+v_{5}^{1}-v_{5}^{1}$ (see, e.g., $[4,5,17]$, and [18]).

Neglecting the pressure and the Doppler broadening within the approximation, the half-width and the depth of the absorption line corresponding to an absorption peak at the given resolution can be determined by the number of weakly coupled molecules $\mathrm{CO}$ and $\mathrm{HF}$.

Let the optical path length $z$ be given. A relatively small change in the transmitted intensity, being integrated over the domain $\Delta \nu$ (see, e.g., Fig. 2), is approximately proportional to the absorption coefficient $\bar{\alpha}(\nu \pm \Delta \nu)$ averaged over the frequency

$$
\Delta I(\nu \pm \Delta \nu) \sim-\bar{\alpha}(\nu \pm \Delta \nu) z \Delta \nu,
$$

where the absorption coefficient is proportional to the number of complexes per unit volume, $n(\mathrm{OC}-\mathrm{HF})$.

The number of complexes is supposed to be proportional to the rate of collisions of molecules of the different species and the probability of a coupling after the collision. The number of collisions per unit time between two kinds of molecules is proportional to the densities of both components CO and HF. In general, the density of complexes can be a quite complicated function of the densities of $\mathrm{CO}$ and HF. In the polynomial approximation for the given initial intensity and a fixed density of $\mathrm{HF}$, we have

$\Delta I(\nu \pm \Delta \nu) \sim B_{1} n(\mathrm{OC})+B_{2} n^{2}(\mathrm{OC})+\ldots$.

To demonstrate the dependence of the absorption on the density of carbon monoxide, Figs. 3 and 4 were drawn in the following manner. The change in the transmitted intensity $\Delta I$ integrated (summed) over the region from $3839.05 \mathrm{~cm}^{-1}$ to approximately 
$3839.3 \mathrm{~cm}^{-1}$ with a step of $0.02472 \mathrm{~cm}^{-1}$ (for the better understanding, see the region on the larger scale in Fig. 2) is shown in Fig. 3.

The change in the transmitted intensity integrated (summed) over the region from $3844.45 \mathrm{~cm}^{-1}$ to $3844.65 \mathrm{~cm}^{-1}$ with a step of $0.02472 \mathrm{~cm}^{-1}$ is shown in Fig. 4.

Note the relatively steep increase of the functions shown in Figs. 2 and 3 in the domain of pressures from 8 to 10 Torr and from 6 to 10 Torr. In addition, the number of collisions per unit time for a molecule (carbon monoxide) with its reaction partner (hydrogen fluoride) decreases with increasing the density of carbon monoxide molecules. This gives a possible interpretation for the negative values of the coefficients $B_{1}$ and $B_{2}$ at the term of the second order in the pressure in expression (2) (see the captions for Figs. 3 and 4).

The possible nonlinear dependence of the integral absorption coefficient on the density of the component can be an evidence of some kind of a complicated mechanism involved in the formation of the complex. For example, in contrast with the classical case of the concave down shape of the reaction rate function for the transition between a linear dependence on the pressure and the independence of the pressure, in the case of the concave up curve in the mentioned domain of pressure, we can assume the following. To create a bound state for hydrogen fluoride and carbon monoxide molecules, the existence of a potential barrier "able to hold" a pair of molecules together at the van der Waals distances during a certain time interval can be deduced under binary collisions. Then, from the quantum mechanical point of view under the defined conditions, the restraining barrier can be overcome for a quite high probability of the tunnel effect. The probability of the tunnel effect in a sample increases with the number of $\mathrm{CO}$ molecules per unit volume. In this case, the probability of tunneling can have a relatively complex dependence on the translational, vibrational, and rotational energies for the coupled molecules $\mathrm{CO}$ and $\mathrm{HF}$.

For example, assume the probability for two molecules to be trapped by a weakly bounding barrier after a binary collision can be defined from the graphs of the pressure dependence:

$\bar{\alpha}(\nu \pm \Delta \nu) \sim T$,

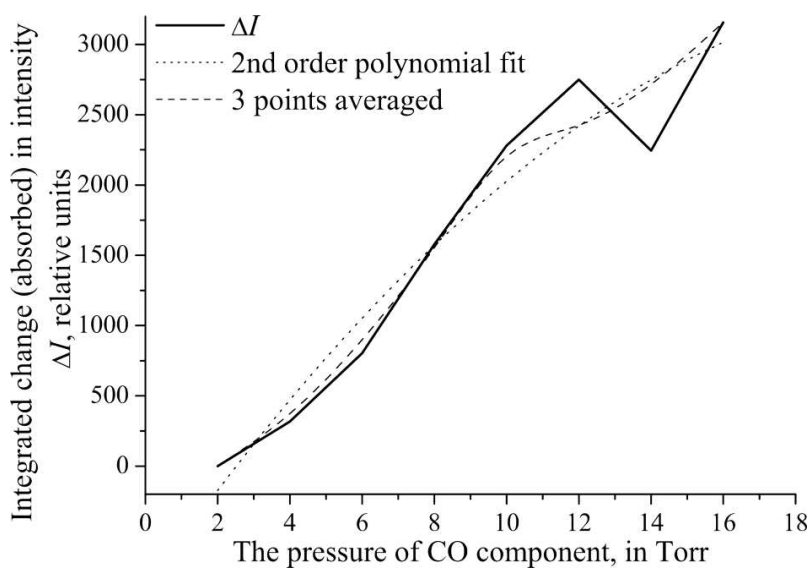

Fig. 4. Integral change in the transmitted intensity $\Delta I$ as a function of the density of carbon monoxide. A vicinity of the $P$-head of the hot band $v_{1}+v_{5}^{1}-v_{5}^{1}$ is depicted. Here, the bold polyline connects the values of $\Delta I$ for different pressures of $\mathrm{CO}$ with a step of 2 Torr. The dotted curve represents the secondorder polynomial fit: $\Delta I \sim B_{1} n(\mathrm{CO})+B_{2} n^{2}(\mathrm{CO})$, where $B_{1} \approx$ 369.4608 and $B_{2} \approx-7.8684$. The dashed curve is a three-point averaged polyline

where $T$ is the transmission coefficient (more accurately, the probability of being transmitted) for the quantum tunneling through the barrier. Then, in the simplest case of a rectangular barrier, the height of the potential barrier (more accurately, its order of value) can be estimated from the expression for the transmission coefficient of a tunneling particle (see, e.g., [19]):

$T(E) \sim \tilde{V}_{0}^{-L}$,

where $\tilde{V}_{0}=e^{2 \sqrt{\frac{2 m}{\hbar^{2}}\left(V_{0}-E\right)}}$. Here, $E$ is the initial kinetic energy of the approaching molecules relative to the center of masses, $V_{0}$ is the height of the potential barrier (it is supposed here that $E<V_{0}$ ), $m$ is the reduced molecular mass, and $L$ is the length of the barrier potential. Because the above expression for the transmission corresponds to a free motion after overcoming the barrier, the actual barrier value can be numerically far from the estimated one. In this case, more adequate results for the potential barrier can be given by the scattering theory with regard for the possible space pairing of two molecules.

The discussed above requires a further investigation in order to be in consistency with the available theoretical results. For example, the transition 
processes during the molecular collisions, leading to the formation of a complex, are not still discovered in the literature. Mainly, the reacted molecules have negative total energy relative to their center of masses for the described model morphed potentials (some analysis is provided, e.g., in [20]). At the same time, the total initial energy before the collision between two molecules, which can be represented as a sum of the kinetic translational, vibrational, and rotational energies, is positive by definition. Some explanations can be provided, of course, with the help of the mechanism of excitation (regrouping) of valent electronic shells during the approach of the reagents to each other. But, in this case, it should be expected, roughly saying, that the energy required for regrouping the shells is of the same order in comparison with the initial total kinetic energy.

\section{Conclusion}

We have presented the transmission broad band spectra of a complex $\mathrm{OC}-\mathrm{HF}$ for various pressures of the $\mathrm{CO}$ component at a given average temperature. The corresponding " $P$-head" graphs of the densitydependent change in the transmitted intensity are obtained in the given approximation. Having the built dependences of the averaged integral absorption coefficient on the densities of the mixture components, the model of weak tunnel reactions can therefore be discussed.

The Robert A. Welch Foundation is thanked for the financial support in the form of pre-doctoral and post-doctoral fellowships under grant A-747. I also thank Dr. J. Bevan's group and the Laboratory for Submm/THz Science and Technology at Texas A \& M University (College Station, Texas, USA) for providing the support and consultations.

1. A.C. Legon, P.D. Soper, and W.H. Flygare, The rotational spectrum, H, ${ }^{19} \mathrm{~F}$ nuclear spin-nuclear spin coupling, D nuclear quadrupole coupling, and molecular geometry of a weakly bound dimer of carbon monoxide and hydrogen fluoride, J. Chem. Phys. 74(9), 4944 (1981) [DOI: 10.1063/1.441747].

2. G.T. Fraser and A.S. Pine, Isotope effects in the highresolution infrared spectrum of OC-HF, J. Chem. Phys. 88, 4147 (1988) [DOI: 10.1063/1.453821].
3. J. Han, A.L. McIntosh, C.L. Hartz, and J.W. Bevan, A rovibrational analysis of the $v_{1}$ and $v_{2}$ bands of $\mathrm{OC}-\mathrm{DF}$ by supersonic jet FTIR spectroscopy, Chem. Phys. Lett. 264, 411 (1997) [DOI: 10.1016/S0009-2614(96)01333-4].

4. Z. Wang and J.W. Bevan, Diode laser spectroscopy of the hydrogen bond vibration $v_{2} \mathrm{OC}-\mathrm{HF}$ in a continuous wave supersonic jet, J. Chem. Phys. 91, 3335 (1989) [DOI: 10.1063/1.457642].

5. K. McMillan, D. Bender, M. Eliades, D. Danzeiser, B.A. Wofford, and J.W. Bevan, Supersonic molecular beam and static gas phase spectroscopy of intermolecular hot bands associated with $v_{1}^{16} \mathrm{O}^{12} \mathrm{C}^{1}{ }^{1} \mathrm{H}^{19} \mathrm{~F}$, Chem. Phys. Lett. 152, 87 (1988) [DOI: 10.1016/0009-2614(88)87333-0].

6. G.A. Jeffrey and W. Saenger, Hydrogen Bonding in Biological Structures (Springer, Berlin, 1991) [ISBN: 3-54050839-2].

7. P. Hobza, in Annual Reports on the Progress of Chemistry, Section C, Physical Chemistry (Royal Soc. Chemistry, Cambridge, 2004), p. 3 [DOI: 10.1039/B313660B].

8. J.E.D. Bene and M.J.T. Jordan, Vibrational spectroscopy of the hydrogen bond: An ab initio quantum-chemical perspective, Int. Rev. Phys. Chem. 18, 119 (1999) [DOI: 10.1080/014423599230026].

9. G. Gilli and P. Gilli, Towards an unified hydrogen-bond theory, J. Mol. Struct. 552, 1 (2000) [DOI: 10.1016/S00222860(00)00454-3].

10. V.K. Pogorelyi, Weak hydrogen bonds Russ. Chem. Rev. 46, 316 (1977) [DOI: 10.1070/ RC1977v046n04ABEH002134].

11. G. Gilli and P. Gilli, The Nature of the Hydrogen Bond: Outline of a Comprehensive Hydrogen Bond Theory (Oxford Univ. Press, Oxford, New York, 2009) [ISBN: 978-019-955896-4].

12. Y. Maréchal, The Hydrogen Bond and the Water Molecule: the Physics and Chemistry of Water, Aqueous and Bio Media (Elsevier, Amsterdam, 2007).

13. J.C. Speakman, The Hydrogen Bond and Other Intermolecular Forces (Chemical Society, London, 1975) [ISBN 10: 085186919X].

14. P. Schuster, G. Zundel, and C. Sandorfy, The Hydrogen Bond: Recent Developments in Theory and Experiments (North-Holland, Amsterdam, 1976).

15. T.A. Dolenko et. al., Raman Spectroscopy of WaterEthanol Solutions: The Estimation of Hydrogen Bonding Energy and the Appearance of Clathrate-like Structures in Solutions, J. Phys. Chem. A 119, 10806 (2015) [DOI: 10.1021/acs.jpca.5b06678].

16. M.S. Ghoraishi et. al., Clustering mechanism of ethanolwater mixtures investigated with photothermal microfluidic cantilever deflection spectroscopy, Sci. Reps. 6, 23966 (2016) [DOI: 10.1038/srep23966].

17. E.K. Kyrö, P. Shoja-Chaghervand, K. Mcmillan, M. Eliades, D. Danzeiser, and J.W. Bevan, Rotational-vibration

ISSN 2071-0194. Ukr. J. Phys. 2016. Vol. 61, No. 9 
analysis of the $n=0, n v_{6}+v_{1}-n v_{6}$ subband in the hydrogen-bonded system ${ }^{16} \mathrm{O}^{12} \mathrm{C} \cdots{ }^{1} \mathrm{H}^{19} \mathrm{~F}, J$. Chem. Phys. 79, 78 (1983) [DOI: 10.1063/1.445516].

18. K.W. Jucks and R.E. Miller, The effect of vibrational state mixing on the predissociation lifetime of $v_{1}$ excited OC-HF, J. Chem. Phys. 86, 6637 (1987) [DOI: 10.1063/1.452410].

19. Mohsen Razavy, Quantum Theory of Tunneling (World Scientific, Singapore, 2003) [ISBN: 981-238-018-3].

20. L.A. Rivera-Rivera, Z. Wang, B.A. McElmurry, R.R. Lucchese, J.W. Bevan, and G. Kanschat, Morphing a Vibrationally-Complete Ground State Potential for the Hydrogen Bond OC-HF, Chem. Phys. 390, 42 (2011) [DOI: 10.1016/j.chemphys.2011.10.001].

Received 15.05.16
A.C. Сіжук

СПЕКТР ПОГЛИНАННЯ СУМІШ СО ТА НF ДЛЯ ЗМІННОї У ЧАСІ ГУСТИНИ СО

Р е $з$ ю м е

Спектри газової фази $\mathrm{CO}$ та НF суміші були отримані у середній інфрачервоній області від 3838 до 3854 хвильових чисел. Використовуючи техніку широкополосного Фур'є сканування, зародження $P$-піків фундаментальної та "гарячої" груп ліній комплексу OC-HF були спостережені при поступовому збільшенні парціального тиску компоненти СО, у той час як кількість молекул $\mathrm{HF}$ та середня температура суміші фіксовані. Залежність інтегральної зміни вихідної інтенсивності від парціального тиску компоненти СО проаналізована для околів 3939,12 та 3944,5 P-піків фундаментальної та “гарячої" груп ліній поглинання, відповідно. 